\title{
Educação e transformação digital: o habitar do ensinar e do aprender, epistemologias reticulares e ecossistemas de inovação
}

\author{
Education and digital transformation: the habit of teaching and \\ learning, reticular epistemologies and innovation ecosystems
}

\author{
Eliane Schlemmer ${ }^{1}$ \\ Leonel Morgado ${ }^{2}$
}

José António Marques Moreira ${ }^{3}$

\section{Resumo:}

As transformações digitais têm provocado alterações na Educação, mas ainda não disseminadas. A compreensão da natureza, limites e potencialidades dessas transformações, exige um repensar das epistemologias e das teorias de aprendizagem. Propomos um quadro de interpretação dessas alterações, que encara o ensinar e o aprender enquanto percursos que se coengendram num habitar e co-habitar cada vez mais atópico, em contextos híbridos e multimodais. Por meio desse quadro, é possivel compreender a transformação digital na Educação enquanto deslocamento disruptivo num espaço-tempo de interações ecossistêmicas de inovação. Este quadro de interpretação nasce do cruzamento das contribuições de Di Felice sobre os movimentos epistemológico do processo de digitalização que nos leva a uma nova condição habitativa, pós-urbana e atópica, originando epistemologias reticulares; e da perspectiva dos ${ }^{1}$ Doutora em Informática na Educação e Mestre em Psicologia pela Universidade Federal do Rio Grande do Sul - UFRGS. Bacharel em Informática pela Universidade do Vale do Rio dos Sinos - UNISINOS. Atualmente, é professora-pesquisadora titular do Programa de PósGraduação em Educação na UNISINO.

${ }^{2}$ Doutor em Ciências da Educação pela Universidade de Coimbra, professor no departamento de Educação e Ensino a Distância da Universidade Aberta de Portugal.

${ }^{3}$ Professor auxiliar com agregação na Universidade Aberta de Portugal.

Interfaces da Educ., Paranaỉba, v.11, n.32, p. 764 - 790, 2020

ISSN 2177-7691 
ecossistemas educacionais como sistemas vivos e cognitivos de Capra, Latour e Di Felice, onde se conectam diferentes ecologias, para além das humanas.

Palavras-chave: Educação. Transformação Digital. Hibridismo. Multimodalidade. Ecossistemas. Inovação.

\section{Abstract:}

Digital transformations have caused changes in education, but not yet disseminated. Understanding the nature, limits, and potentialities of these transformations requires a rethinking of epistemologies and learning theories. We propose a framework for interpreting these changes, which views teaching and learning as paths that are co-engendered in an increasingly atopic dwelling and co-dwelling, in hybrid and multimodal contexts. Through the framework, it is possible to understand the digital transformation in education as disruptive displacement in space-time of ecosystem interactions of innovation. This framework of interpretation arises from the intersection of Di Felice's contributions on the epistemological movements of the digitization process that leads us to a new inhabiting condition, post-urban and atopic, originating reticular epistemologies; and from the perspective of educational ecosystems as Capra, Latour, and Di Felice's living and cognitive systems, where different ecologies connect in addition to human ones.

Keywords: Education. Digital Transformation. Hybridism. Multimodality. Ecosystems. Inovation.

\section{Educação e Transformação Digital}

Vivemos a quarta revolução industrial (SCHWAB, 2016) provocada, principalmente, pelo desenvolvimento das pesquisas na área da Ciência da Computação. Essa revolução é marcada pela emergência acelerada de diferentes Tecnologias Digitais (TD), interligadas por redes de comunicação Interfaces da Educ., Paranaíba, v.11, n.32, p. 764 - 790, 2020 
sem fios, capazes de conectar, de forma inteligente, pessoas, coisas e lugares, ou seja, anything, anywhere, anytime, bem como mapear os percursos dessa conexão e fazer recomendações. A Internet das Coisas Internet of Things (IoT), a Inteligência Artificial (IA), as Redes Neurais, o Big Data, os Learning Analytics, o Deep Learning, entre outras aplicações que exigem processamento de imensos dados simultaneamente, impulsionam as pesquisas para o desenvolvimento da computação quântica ${ }^{1}$, o que tornará os computadores ordens de grandeza mais poderosos do que os supercomputadores atuais.

Esse desenvolvimento tecnológico impulsiona o surgimento de sistemas ciber-físicos que possibilitam a construção de ecossistemas, tornando o mundo mais conectado e inteligente e, dessa forma transformando a experiência humana em diferentes sentidos e contextos, por meio da constituição de múltiplas redes sociotécnicas de toda a natureza e com distintos objetivos. Isso modifica/amplia, significativamente, a nossa compreensão de espaço e tempo, bem como a nossa condição habitativa (DI FELICE, 2009). De acordo com Castells (1999) o espaço de lugares, enquanto espaço físico, geográfico, se prolonga em espaço de fluxos, constituído pelas redes digitais. Isso faz com que a nossa condição habitativa se transforme, uma vez que não está mais vinculada somente aos espaços físicosgeográficos, mas também aos espaços digitais. O tempo passa a ser compreendido segundo a simultaneidade e intemporalidade, permitindo que a comunicação em rede se dê por meio de diálogo síncrono e assíncrono, tornando a interação possivel em qualquer tempo. Interação que pode ser

\footnotetext{
${ }^{1}$ Enquanto na computação clássica temos o bit, assumindo somente dois estados binários 0 ou 1, na computação quântica, por meio do conceito de superposição, temos o qubit (versão quântica dos bits tradicionais), que pode ser 1,0 ou ambos simultaneamente, o que faz com que mais operações possam ser realizadas simultaneamente. Note-se que o aumento de capacidade computacional dos computadores clássicos, na segunda metade do século XX, transformou-os de máquinas que nos ajudavam a fazer contas, para máquinas que nos ajudaram a tomar decisões, a reintrepretar o mundo e a comunicar de forma completamente distinta, mudando assim a sociedede (Morgado, 2005, cap. 2.2). Se este aumento da capacidade computacional que se espera da computação quântica permitir atacar problemas que hoje são intratáveis, ou seja, que demoram demasiado tempo a resolver, como será no futuro quando esse tipo de cálculos passar a estar disponível num período de tempo utilizável? Que áreas da vida humana se transformarão?
} 
retomada, remixada e retornada ao contexto comunicacional em diferentes tempos.

Para melhor compreender as transformações digitais que estamos vivenciando, retomamos o processo histórico da conectividade da Internet a fim de ressignificá-lo.

A história da conectividade digital tem início com a invenção da Internet, no final do século XX e, segundo Allen (2013), se populariza com a chegada da visualização de documentos interligados entre si, permitindo a navegação automática visual entre eles - a primeira versão da World Wide Web, ou Web 1.0. No início dos anos 2000, a partir de novas soluções tecnológicas, os navegantes passaram não apenas a consultar documentos ou a preencher formulários, mas a modificá-los interativamente, complementando-os com comentários ou outros elementos, criando novos documentos diretamente na Web, desenvolvendo comunidades de debate, contribuindo para a produção do conhecimento e publicação de forma mais imediata. Quebrou-se a separação entre os atos de produção e de consumo do conteúdo, convergindo ambos os atos numa osmose de produção e consumo. Todos somos, desde então, produtores-consumidores, seja em blogues, mídias sociais, plataformas de debate e partilha, ou quaisquer outras. Esta mudança paradigmática da interação na Web foi denominada Web 2.0. Mais recentemente novas tendências surgiram, cada qual prometendo - e frequentemente concretizando - novas transformações radicais no paradigma da interação e no papel dos produtores/consumidores face à tecnologia. Por exemplo, a IoT, que liga à Internet dispositivos até então inertes, como válvulas de água, câmaras de videovigilância, termômetros domésticos, biossensores implantados em animais ou praticamente qualquer outro ponto onde se encontre tecnologia digital. Falamos de objetos e aparelhos, mas também de mercadorias, de seres vivos ou até mesmo de superficies. Quase que cada elemento do mundo passou a poder produzir conteúdo vertido na Internet.

Esta grande quantidade de dados provenientes das interações das pessoas (produtores-consumidores) e das coisas criou um grande potencial Interfaces da Educ., Paranaíba, v.11, n.32, p. 764 - 790, 2020 
de descoberta de padrões e de relações até então indetectáveis. De possibilidades de atuação e de decisão impensadas, potencial expresso no conceito "Big Data". Esta diversidade de fontes de dados e dos próprios dados cruzou-se com as tendências já em desenvolvimento na área da detecção de padrões e da IA, permitindo transformações inesperadas. Por exemplo, a interpretação da voz humana, um problema longamente atacado, passou de aceitável a muito bem-sucedida em poucos anos, graças à possibilidade de receber em pontos centrais (computadores-servidores na Internet), massivamente, exemplos de voz gravada, acompanhados de dados contextuais ricos ("voz gravada numa aplicação de mapas, quando a pessoa está nesta localidade e tem por hábito deslocar-se a esta hora para ali"; "voz com o sotaque de muitas outras pessoas desta região"; "voz gravada a esta hora, onde muita gente costuma procurar restaurantes"; etc.). Eficácia semelhante na visão por computador, ligada à Internet, originou capacidades insuspeitadas na condução de carros de forma autónoma ou na detecção de rostos em câmaras de videovigilância ou ainda fotografias de eventos. Esta área, que emergiu no mercado dos chavões como "Machine Learning", revelou também capacidades de decisão automática por parte de programas com potencial computacional muito inferior à que se julgava necessária para o conseguir. Revelou ligações complexas e desafiantes entre os trabalhos na área da neurologia e da informática, quanto à emergência da consciência ou da vida. Em suma, as transformações não são apenas otimizações ou aceleração do que já existe, mas sim, verdadeiras recriações do mundo, alterações que abrangem todas as áreas do saber, do agir e da nossa visão e presença no mundo. Frente a esse contexto histórico Di Felice $(2019)^{2}$, refere que o processo de digitalização pode ser compreendido como:

- um progressivo processo de expansão de redes (computador, pessoas, coisas, dados, ....);

\footnotetext{
${ }^{2}$ Em comunicação oral, disponível em https://www.youtube.com/watch?v=zCg5H7RcIq0\&t=7791s Interfaces da Educ., Paranaíba, v.11, n.32, p. 764 - 790, 2020
} 
- uma ampliação e incremento de formas de conectividade que nos conectou a outras pessoas, as coisas, a biodiversidade e a tudo o que existe, o que remete a natureza conectiva do humano.

- um processo generalizado de datatização, de transformação de tudo o que existe em dados. Com a IoT um objeto, mercadoria é conectado a rede e, para além de transmitir dados, sofre alteração no seu estatuto enquanto é representado por esses dados. Isso é válido para tudo, uma vez que tudo são dados convertidos em formatos digitais e, portanto, se torna um processo de transformação que altera o estatuto da realidade.

- um processo de transfiguração do mundo. Não se pode pensar a Internet, a digitalização, apenas na perspectiva da computação ou da comunicação. O processo de transformação se refere a natureza da matéria - de átomo para bit, às ecologias e também ao humano.

No âmbito da Educação, Schlemmer e Moreira (2019), referem que todas essas transformações nos possibilitam falar de um viver, conviver e aprender, não somente de natureza analógico-geográfica (off-line), mas de natureza digital (on-line). Segundo Moreira (2018), o fim da distinção entre o off-line e o on-line e a proposição do neologismo onlife, é defendido no Onlife Manifesto - Being Human in a Hyperconnected Era $(2015)^{3}$, ao referir-se a uma nova realidade hiperconectada, onde se afirma: Dualism is Dead! Long Live Dualities!

É nessa realidade hiperconectada que emergem diferentes contextos educacionais, apontados por relatórios internacionais. Entre eles o Educause Horizon Report - 2019 Higher Education Edition ${ }^{4}$, o qual refere como tendências no período de um ano ou menos, a presença do Mobile Learning, aumento da apropriação da realidade expandida $\left(\mathrm{XR}^{5}\right)$ e, adoção de tecnologias analiticas, possibilitando análise dinâmica, conectada, preditiva

\footnotetext{
${ }^{3}$ Disponível em https://link.springer.com/content/pdf/10.1007\%2F978-3-319-04093-6.pdf ${ }^{4}$ https://library.educause.edu/-

/media/files/library/2019/2/2019horizonreportpreview.pdf

${ }^{5} \mathrm{XR}$ - Realidade Expandida - é a categoria que envolve todas as várias formas de realidade alterada por computador, tais como: Realidade Virtual, Realidade Aumentada e Realidade Mista
}

Interfaces da Educ., Paranaíba, v.11, n.32, p. 764 - 790, 2020 
e sistemas e dados personalizados. Como tendência para dois ou três anos, a adoção da Realidade Mista, no cruzamento on-line e off-line, onde coexistem objetos digitais e físicos. Este espaço híbrido integra tecnologias analógicas e digitais, desfocando a diferenciação entre os dois mundos. Nesse contexto temporal, também estão os dispositivos holográficos e a IA. Como tendência para quatro ou cinco anos, a adoção da tecnologia Blockchain, permitindo ampla solução ecossistêmica. Ao possuir características descentralizadas de verificação e armazenamento, atores diversos podem validar registos sem depender de entidades certificadoras centralizadas. Ela poderá estar presente mais como algo que inspira novas formas de organização do que propriamente na tecnologia em si. E, ainda Assistentes Virtuais, tais como Siri, Alexa, Bixby ou Google Assistant.

Para além desses movimentos, presenciamos o surgimento de cursos totalmente gamificados, cuja progressão nas disciplinas e semestres ocorre a partir da lógica (mecânicas e dinâmicas) dos games, como a proposta das Escolas $42^{6}$. Aulas com professores holográficos ${ }^{7}$, como a experiência em desenvolvimento pelo Imperial College, em Londres. A realização da mediação da aprendizagem por Agentes Comunicativos com alto nivel de IA. Aulas dadas por autômatos, também conhecidos como robôs (humanóides e andróides) como os desenvolvidos pelo pesquisador roboticista Ishiguro Hiroshi ${ }^{8}$, sendo um exemplo, o androide teleoperado de Ishiguro, Geminoid H1-2, seu gêmeo criado para dar aulas quando o professor está impossibilitado.

É possivel citar, ainda, a Analitica Aumentada, que faz uso de Machine Learning para transformar a forma como o conteúdo analítico é produzido, consumido e compartilhado, propiciando o desenvolvimento da "Ciência de dados cidadã - um conjunto emergente de recursos e práticas que permite aos usuários finais extrair insights preditivos e prescritivos dos

\footnotetext{
6 https://www.42.us.org/

7https://epocanegocios.globo.com/Tecnologia/noticia/2018/11/universidade-britanicaonde-hologramas-seraoprofessores.html?utm_source=facebook\&utm_medium $=$ social\&utm_campaign=post\&fbclid=I wAR0GUmWCh_HKKO94QKXsL7EML1FaqQ2uvz13ZaeiY8JI_Qf4lsyvSc_xHY4 8 Intelligent Robotics Laboratory, Osaka University - https://eng.irl.sys.es.osaka-u.ac.jp/ Interfaces da Educ., Paranaíba, v.11, n.32, p. 764 - 790, 2020
} 
dados"9. Gêmeos Digitais de organizações - DTO10 (representação digital que fazem uso também de sensores), já existentes no mundo geográfico para o digital, o que irá potencializar a capacidade de coletar, visualizar e trabalhar com dados da realidade, resultando em processos mais flexíveis, dinâmicos e responsivos, que podem reagir às mudanças de condições automaticamente. Experiências Imersivas, com tecnologia de XR, fazendo pontes entre o mundo geográfico e digital, hibridizando espaços urbanos e pós-urbanos, o que potencializa um habitar atópico ${ }^{11}$ (DI FELICE, 2009). Essas experiências híbridas e multimodais conectarão pessoas com o mundo digital, lugares e coisas a partir de uma infinidade de dispositivos periféricos que incluem desde sensores espalhados pelo espaço geográfico até as tecnologias vestíveis - wearables. Espaços inteligentes (cidades inteligentes, digital workplaces, residências inteligentes e fábricas conectadas) que podem se referir a espaços físicos, digitais ou ainda híbridos, habitados por humanos e dotados de alta TD, impulsionando a criação de ecossistemas cada vez mais conectados, inteligentes e autônomos, o que potencializa experiências mais imersivas, interativas, automatizadas e contextualizadas.

Todas essas transformações vêm contribuindo para nos aproximar e nos unir numa grande comunidade global ciber-física, potencializando a comunicação, a colaboração e a cooperação entre entidades e organizações de diferentes naturezas. Essa potencialidade torna possivel reunir nações e

9https: / / cio.com.br/10-tendencias-tecnologicas-estrategicas-para-2019-segundo-ogartner/?fbclid=IwAROic0xjUJVEH97dvt93VKbwHh3vnUMNtcFNMgkSkvIrHKrR2rQ4NoVTzw

10 modelo de software dinâmico baseado em dados operacionais ou outros com o objetivo de compreender como uma organização operacionaliza seu modelo de negócios, se conecta com seu estado atual, implementa recursos e responde a mudanças para entregar o valor esperado ao cliente.

11 atopia não é um novo tipo de espaço, nem um território simulacro, nem poderia ser definida inteiramente como uma pós-territorialidade, no sentido único da superação das formas físicas e geográficas do espaço. Melhor seria defini-la como a substituição destas por uma forma informativa digital e transorgânica, cujos elementos constitutivos são as tecnologias informativas digitais, os ecossistemas informativos elaborados pelos sistemas informativos geográficos e territoriais e as redes sociais, compostas pela fusão de elementos inteligentes e pelas formas híbridas do dinamismo das linguagens transorgânicas. O habitar atópico se configura, assim como a hibridação, transitória e fluida, de corpos, tecnologia e paisagem, e como o advento de uma nova tipologia de ecossistema, nem orgânica, nem inorgânica, nem estática, nem delimitável, mas informativa e imaterial” (Di Felice, 2009, p. 291.)

Interfaces da Educ., Paranaíba, v.11, n.32, p. 764 - 790, 2020 
pessoas para pensar na complexidade ecossistêmica do mundo atual e compreender como a relação entre atores humanos $(\mathrm{AH})$ e não humanos (ANH), com o meio ambiente orgânico e/ou inorgânico que habitam, e pelo qual também são habitados, se transforma. Em como vamos educar a atual e as futuras gerações para desafios reais como o aquecimento global, terrorismo, racismo, tráfico, dentre outros, bem como desenvolver competências para profissões que ainda estão por ser inventadas, considerando que devido a esse avanço tecnológico, o mundo do trabalho tem se transformado significativamente.

É fato que a conectividade e o habitar atópico (DI FELICE, 2009) potencializados pela rede, está se tornando um novo princípio organizativo da espécie humana. Parag Khanna (2016) utiliza o termo "conectografia" para evidenciar um mundo onde a conectividade permite ultrapassar limitações físicas da Geografia. Nesse contexto, Schwab (2016) refere a necessidade de um progresso social que possa minimizar as desigualdades sociais. Segundo o autor, faz-se necessário compreender o conceito de abertura, como uma forma de soberania; a tecnologia, por meio de expressões como a IA, redes neurais, robótica, IoT, wearables, big data, nanotecnologia, dentre outras e; a educação, como instrumento fundamental para inventividade e construção da inovação. Segundo a WEF (2015) e Brasil (2018), países e regiões que exploram plenamente estas tecnologias estarão na vanguarda das economias avançadas e sustentáveis. Referem ainda, a preocupação com relação aos desafios e oportunidades que geram para as nações e, principalmente, para educação.

Entre os desafios, no campo da educação, está a necessidade de formar pessoas que sejam capazes de aprender, viver, conviver e atuar nessa sociedade hiperconectada, de maneira responsável, crítica e cidadã, a fim de transformá-la. Para tal, a inovação e as tecnologias precisam estar focadas nas humanidades e no necessário desenvolvimento social e ambiental sustentável. Preocupação que também é referida na Estratégia Brasileira para a Transformação Digital - e-Digital (BRASIL, 2018) e em documentos internacionais para o desenvolvimento, como a Agenda 2030 das Nacõoes 
Unidas, especialmente, quanto aos objetivos: "Educação de Qualidade" e "Cidades e Comunidades Sustentáveis" (SCHLEMMER, LOPES, AMARAL e FISCHER, 2018, p. 1).

Os conhecimentos, as capacidades, as atitudes $\mathrm{e}$ valores $\mathrm{e}$, as competências para atuar profissionalmente precisam ser desenvolvidas numa ambiência formativa e de pesquisa, marcada pela interdisciplinaridade, transdisciplinaridade e internacionalidade. Mobilizadas num imbricamento de tecnologias digitais, físicas e biológicas, numa perspectiva reticular, conectiva e atópica, que instigue o pensamento divergente, criativo e inventivo, nos permitindo ser e estar num mundo totalmente integrado, e no qual temos o desafio de estabelecer as bases para as inovações, a partir de um pensar e agir em nível glocal.

É fato que a transformação digital, ciber-física, vem exigindo o desenvolvimento de outra ordem de competências, para além das consideradas fundacionais, como a literacia e cálculo. Essas representam apenas o ponto de partida do caminho para a mestria das competências consideradas chave do século XXI, como a comunicação, a colaboração, a criatividade e o pensamento crítico e resolução de problemas (WEF, 2015) e, ainda, a curiosidade, a iniciativa, a cooperação e a inventividade (KASTRUP, 2015), e a capacidade de lidar com a complexidade emergente - complex learning (FERNANDES, MORGADO, PAREDES, COELHO e RICHTER, 2019).

Ora, perante esta nova realidade cada vez mais híbrida e hiperconectada, torna-se necessário criar mecanismos de promoção destas competências que, como destaca o WEF, estão ainda aquém do desenvolvimento esperado na grande maioria dos países. É, pois, necessário repensar o paradigma educacional, para além das "competências fundacionais", porque hoje o mundo (do trabalho) exige saber trabalhar em equipe, avaliar criticamente a informação e produzir conhecimento, tanto quanto o desenvolvimento de qualidades como a persistência ou a adaptabilidade, que asseguram uma maior resiliência e capacidade de superação de obstáculos (WEF, 2015). 
Vários estudos internacionais, para além do já citado do WEF, como o Partnerships for the 21st Century Skills (P21)12 e o estudo da Rede Europeia de Politicas sobre as Competências Essenciais na Educação Escolar (KeyCoNet) ${ }^{13}$, apontam também para dominios comuns e específicos, como as Competências Comunicacionais, referentes à capacidade de comunicação oral e escrita, de literacia para as tecnologias e para os média; as Competências de Raciocinio e Resolução de Problemas e as Competências Interpessoais e de Autodirecionamento, referentes à colaboração e trabalho em equipe, à sensibilidade e responsabilidade social, à adaptação e flexibilidade, à curiosidade e criatividade e, finalmente, à autonomia e à iniciativa, fundamentais para a atuação do ser humano nesta sociedade com múltiplas configurações.

Assim, é fácil compreender porque a discussão sobre a emergência acelerada de diferentes TD, interligadas por redes de comunicação sem fios e, as transformações que podem promover na educação, nomeadamente, no que diz respeito ao desenvolvimento destas competências, estão na centralidade das agendas de pesquisa em nivel global. As Humanidades Digitais ou ainda as Pós-humanidades (DI FELICE, 2009), onde os híbridos adquirem destaque nos possibilitam falar de um viver, conviver e aprender, onlife, numa rede que interliga natureza, técnica e cultura. É nessa realidade hiperconectada, na qual é possivel desenhar diferentes cenários educacionais, que problematizamos o habitar do ensinar e do aprender no contexto das epistemologias reticulares (DI FELICE, 2012), buscando a superação de uma compreensão de conhecimento antropocêntrica e de uma compreensão do processo educativo centrado no objeto ou professor ou sujeito (aluno), predominantemente circunscritos ao espaço da sala de aula física-geográfica, para a construção de ecossistemas de inovação na Educação.

12 https://www.21stcenturyskills.org 


\section{Epistemologias reticulares e ecossistemas de inovação na Educação}

Uma epistemologia se ocupa de questões relacionadas ao conhecer. É o estudo sobre a origem do conhecimento, sobre como conhecemos o mundo. Esse conhecer, na contemporaneidade, é mediado por redes e existe, ele mesmo, em rede, sendo objeto de estudo de diferentes áreas do conhecimento.

O conceito de rede, a partir de Latour (2012) é compreendido como o movimento associativo que forma o social, sendo antes um instrumento de análise, do que objeto dela. Nesse contexto, o autor refere a necessidade de repensar o conceito de social, enquanto rede de $\mathrm{AH}$ e $\mathrm{ANH}$, onde ator é qualquer pessoa, coisa, (quase) objeto, instituição ou até conceito. Algo que produz agência, ou seja, aquele que tem a propriedade de produzir efeito na rede (ainda que indiretamente), de ser actante. A compreensão de agência está relacionada aos AH e ANH simetricamente, os quais participam das ações e provocam transformações na rede, em movimento. Dessa forma, o não humano deixa de ser considerado somente como um artefato, cuja significação é atribuída pelo humano e, passa a ter agência, ao participar das ações nas situações cotidianas e provocar transformações. Os ANH também interferem nos acontecimentos, na criação de significados, atuando na esfera reflexiva e simbólica. A partir dessa compreensão do que é social, o conceito de rede é entendido como algo vivo, mutável - fluxos, circulações, alianças e movimentos de uma série de elementos animados e inanimados, físicos e etéreos - e não como entidade fixa, reduzida a um conjunto de atores. Refere-se a transformações, translações, deslocamentos, portanto, bem distinta da tradicional compreensão de rede, enquanto forma ou estrutura.

Segundo Di Felice (2019) nós humanos, estamos biologicamente vocacionados à conexão e a conectividade. Nos conectamos com o ar, somos compostos por proteínas, água, elementos que muitas vezes julgamos ser externos, mas que nos compõem. E, no contexto da digitalização, da conectividade, o modelo comunicativo de redes se baseia nessa vocação: a conectividade que marca a espécie humana. Para Di Felice $(2012,2014)$, o Interfaces da Educ., Paranaíba, v.11, n.32, p. 764 - 790, 2020 
termo-chave é "reticular": próprio de redes. Pode ser compreendido enquanto o que se desenvolve no interior de um ecossistema complexo por meio da colaboração de diversos actantes (circuitos informativos, interfaces, mídias, corpos, paisagens, conceitos e ideis, etc.).

Diferentemente da complexidade sistêmica (cuja totalidade é maior que a soma das partes, uma vez que comporta as partes e, principalmente, as relações entre elas), a forma-rede tem um caráter cognitivo e apresenta-se como uma série infinita de redes interagentes que possui uma arquitetura tanto interna, quanto externa e se ocupa do devir (característica atópica) por estar num movimento contínuo de interações, que alteram suas partes, provocando rachaduras, desequilíbrios, transformações em toda a rede. Numa rede, somos membros e não somente observadores. A partir dessa compreensão, segundo Di Felice, Torres e Yanaze (2012), não é possível pensar a rede das redes, enquanto um sistema superior (rede superior) formado pela soma de seus subsistemas (redes inferiores). Um conjunto de redes com alto nível de interações, revela um novo tipo de complexidade, melhor compreendida a partir da lógica conectiva e ecossistêmica e não da lógica sistêmica. A dimensão ecossistêmica "reúne seus diversos membros em um novo tipo de social, não apenas limitado ao âmbito humano dos 'socius', mas expandido às demais entidades técnicas, informativas, territoriais, de forma reticular e conectiva" (Di Felice, 2013, p. 10).

A partir da compreensão desses conceitos Di Felice (2014), refere a necessidade de pensarmos nas epistemologias reticulares, a qual

...exprime uma evidente contradição, de um lado os conhecimentos
(episteme) próprios da mente e dos métodos de conhecimento, do
outro, as redes, as linguagens dos instrumentos técnicos utilizados
para a observação e todos os atores que contribuem à produção do
conhecimento científico. O ponto de partida é a constatação da
característica não exclusivamente humana do conhecimento
produzido pelos humanos. (Di Felice, 2014) ${ }^{14}$

Segundo o autor, a produção do conhecimento sempre se deu em rede, por meio de um diálogo fértil entre a mente humana e outras formas de 
inteligência. Trata-se de uma ecologia complexa que age na medida em que é estimulada pela linguagem e circuitos informativos não humanos. Como exemplos cita: o alfabeto, a escrita, o telescópio, a Web, o Big Data. A diferença é que hoje, a IA e as redes neurais se articulam, conectando-se a bancos de dados digitais, possibilitando a mineração desses dados, bem como a sua prospeção analítica e a produção de novos dados, em rede.

Considerando a perspectiva trazida por Latour (2012, 2016) e Di Felice (2013) e o fato de que na atualidade, as redes digitais, por meio da IA e das Redes Neurais possuem uma inteligência de natureza de máquina, a qual pode potencializar o diálogo, fazendo emergir sínteses e narrativas da complexidade, seria possivel, conforme refere Di Felice (2013), superar essa narrativa auto-centrada do humano, essa visão antropomórfica e antropocêntrica do conhecimento, para então estar aberto para um dimensão transorgânica e trans-linguística da inteligência?

\begin{abstract}
A epistemologia ocidental tem preferido construir a narrativa que se vê como artifício único da nossa inteligência, os sujeitos pensantes ocupados na compreensão e no conhecimento da natureza e do universo. Convém hoje à espécie humana distanciar-se de tal narrativa e se pensar como parte de outras inteligências, cuja complexidade nos proporciona a possibilidade de importantes mudanças. A lógica da dominação do homem e do sujeito racional e político sobre o mundo, sucede aquela da relação, da conexão e do diálogo entre diversas linguagens e inteligências. (Di Felice, 2014) ${ }^{15}$
\end{abstract}

Capra (1996), faz referência a um ecossistema inteligente, compreendido como a interconexão entre os sistemas cognitivos-perceptivos e as arquiteturas informativas, superando a concepção instrumental da mídia e, apontando para uma nova percepção ecológica na qual os elementos, a ambivalência e a tecnologia da informação são partes integrantes do sistema cognitivo, inaugurando uma nova prática do habitar.

A partir dessa perspectiva, podemos pensar os Ecossistemas educacionais como sistemas vivos e cognitivos, os quais coengendram diferentes ecologias ${ }^{16}$, para além do humano. Nesse contexto, contemplamos,

\footnotetext{
15 disponivel em https://www.massimodifelice.net/epistemologia-reticulares-

16 entre elas a ecologia cognitiva, a ecologia social e a ecologia pedagógica.
}

Interfaces da Educ., Paranaíba, v.11, n.32, p. 764 - 790, 2020 
a partir de Di Felice (2019), as ecologias do conhecimento em tempos de programação do mundo, ou seja, aquelas relacionadas a emergência de plataformas de conectividade, de compartilhamento de informações e produção de conteúdos e, as ecologias do conhecimento em tempos de automatização do mundo, evidenciadas pela tecnologia de IoT, IA e deep learning.

Nos interessa saber, entretanto, como as epistemologias reticulares e essas novas ecologias do conhecimento podem contribuir para pensarmos em ecossistemas de inovação na educação, uma vez que tanto Latour, quanto Di Felice referem que o conhecimento e a inteligência não são atividades exclusivamente humanas. Como esses ecossistemas podem potencializar o surgimento de novos espaços e um novo habitar do ensinar e do aprender?

A partir do que propõem Capra (1996), Latour (2012), Di Felice, Torres e Yanaze (2012) entendemos ecossistemas de inovação na educação como ecossistemas complexos, que se constituem por redes de redes de relações conectivas entre $\mathrm{AH}$ e ANH (instituições, governos, empresas, cidade/bairro/vila/comunidade, plataformas, sistemas, interfaces, mídias, corpos, etc.), ou seja, múltiplas redes que coengendram diferentes actantes, a fim de potencializar os espaços educacionais e o habitar do ensinar e do aprender.

Nessas relações conectivas a compreensão de interação muda, pois não mais se supõe a preexistência dos dois termos (organismo e meio, sujeito e objeto) que interagem, mas sim, entende-se a interação como constituição de si e do meio, ou seja, o que enatua nesse autoengendramento (PASSOS, 2015). Não se trata de AH e ANH isoladamente, mas das relações e processos que se constituem a partir dessa nova compreensão de interação. Dessa forma, Latour e Serres nos auxiliam ao trazer o hibridismo para a interação, numa simbiose entre natureza, técnica e cultura. Isso nos possibilita pensar nos diferentes atores intervenientes que agem e interagem, produzindo e recebendo interferências constantes, constituindo alianças. Ou seja, emerge daí, uma nova relação Interfaces da Educ., Paranaíba, v.11, n.32, p. 764 - 790, 2020 
simbiótica, que se afasta tanto do paradigma tecnocêntrico, quanto antropocêntrico, contribuindo para o surgimento de cultura planetária e ecossistêmica.

Isso nos ajuda a entender um ecossistema de inovação na educação como movimento reticular e conectivo, entre $\mathrm{AH}$ e $\mathrm{ANH}$, que se constitui em espaços urbanos e pós-urbanos, no contexto de uma cultura híbrida e multimodal, potencializando o habitar atópico do ensinar e do aprender.

\section{O habitar do ensinar e do aprender ao longo das transformações digitais}

Segundo Schlemmer et al. (2006); Trein e Schlemmer (2009); Schlemmer, Trein e Oliveira (2008) e; Schlemmer e Backes (2015), o habitar, o co-habitar, o e-habitar e o e-co-habitar consistem além da ideia de estar, morar, residir, sobretudo de viver e conviver em diferentes espaços que podem ser físicos-geográficos e/ou digitais-virtuais. Ao nos apropriarmos desses espaços, vamos modificando-o e, também somos modificados por ele. Dessa forma habitamos e e-co-habitamos nossas casas, bairros, cidades e; ehabitamos e e-co-habitamos plataformas, jogos, dentro outras TD. Esse viver e conviver, quando ocorrem em espaços digitais-virtuais ou híbridos, ampliam significativamente as compreensões sobre a relação e interação entre humanos e não humanos e, na medida em que esses entram em congruência, possibilitam transformações em ambos. Nesse processo, a nossa corporalidade e presença também são modificadas, ampliadas, por meio de diferentes formas de representação. Nuances que o "eu" do ser humano atribui aos diferentes "eus digitais-virtuais", definindo-se e revelando-se numa relação que é recursiva.

Para compreender essas diferentes formas de habitar na relação com os processos de ensino e de aprendizagem, retomamos o processo histórico da transformação digital, apresentado anteriormente.

A Web 1.0 tinha como característica principal disponibilizar a informação para ser acessada pelos usuários, os quais eram consumidores dessa informação. O ato de produção, ainda que democratizado face à publicação tradicional em papel ou outros suportes físicos, exigia uma Interfaces da Educ., Paranaíba, v.11, n.32, p. 764 - 790, 2020 
separação do ato de consumo: ao ler, não podiamos responder nem comentar. Não podiamos editar e nem contribuir. Era preciso iniciar uma nova publicação, em novo local, esperando que fosse possível que a comunidade se apercebesse do vínculo entre a origem e a resposta. O produtor e o consumidor, ainda que pudessem ser a mesma pessoa, eram-no em momentos diferentes, vincadamente separados. Nesse contexto, o ensinar e o aprender estavam condicionados, não a uma condição habitativa, mas a uma relação de uso, de consumo da informação préexistente. Havia um controle do conteúdo.

Com a Web 2.0 os sistemas passaram a possibilitar a interação, a colaboração e a cooperação imediatas entre os sujeitos e os documentos. Os sujeitos, de usuários-consumidores, passaram a ser autores-produtores. De acordo com Trein e Schlemmer (2009) nesse contexto, surgiu a Wikipédia, uma enciclopédia aberta e totalmente construída em rede, pelos seus colaboradores. Dessa forma, o ensinar e o aprender passaram a ser potencializados pelas interações em rede, tornando a Web um ambiente que se atualizava constantemente, pela autoria e produção individual e/ou colaborativa e cooperativa dos sujeitos. Dessa forma, para além do uso da tecnologia (perspectiva de usuário-consumidor) tornava-se possivel uma apropriação da tecnologia (perspectiva de autor-produtor-consumidor), favorecendo o habitar do ensinar e do aprender, uma vez que as tecnologias passaram a representam um lugar onde o sujeito estava enquanto autorprodutor de um mundo. Com a Web 2.0 surge a possibilidade da apropriação do conceito de inteligência coletiva ${ }^{17}$, como uma forma de conhecimento colaborativo entre humanos.

Essa tecnologia evoluiu com o surgimento da IoT, com o desenvolvimento da IA, entre outras, possibilitando constituir redes

17 Trata-se de uma inteligencia variada, distribuída por toda parte, constantemente valorizada, coordenada em tempo real, que resulta em uma mobilizac,ão efetiva das competências. A finalidade dessa inteligência é colocar os recursos de grandes coletividades a servic,o das pessoas e dos pequenos grupos, constituindo dessa forma um projeto fundamentalmente humanístico. "A inteligência coletiva, enfim, seria o modo de realizacão da humanidade que a rede digital universal favorece, sem que saibamos a priori em direcão a quais resultados tendem as organizac,ões que colocam em sinergia seus recursos intelectuais". (LÉVY, 1999, p.132). 
inteligentes de interação não somente entre pessoas, mas também entre locais, objetos, coisas, ou seja, tudo o que pode ser conectado a Internet. Nesse contexto, o ensinar e o aprender passam a ser potencializados, por meio de atos conectivos ${ }^{18}$, em uma rede de $\mathrm{AH}$ e $\mathrm{ANH}$, de forma pervasiva e ubíqua, potencializando uma nova condição habitativa do ensinar e do aprender, um habitar atópico, sensivel ao contexto, o que favorece a apropriação da tecnologia enquanto invenção. Esse habitar atópico do ensinar e do aprender pode se dar simultaneamente em contextos físicosgeográficos e nas redes digitais virtuais, de forma hibridizada e multimodal.

O hibridismo se fundamentado no conceito de híbrido para Latour (1994, 2012) e, de acordo com Schlemmer (2013, 2014, 2015a, 2015b, 2016a, 2016b, 2017, 2018) e Schlemmer, Backes e La Rocca (2016) é compreendido a partir do fluxo das ações, interações e comunicação entre $\mathrm{AH}$ e ANH; em espaços geográficos e digitais, incluindo o próprio espaço híbrido; pela presença física e digital virtual (perfil em mídia social, personagem em jogo, prop ou avatar em metaversos, por webcam ou ainda por holograma), portanto, presenças plurais; por meio de tecnologias analógicas e digitais integradas, que juntas favorecem diferentes formas de comunicação e interação (textual, oral, gráfica e gestual); num imbricamento de diferentes culturas (digitais, pré-digitais, tribais, eruditas, dentre outras), constituindo-se em redes e fenômenos indissociáveis, interligando naturezas, técnicas e culturas.

A multimodalidade é apresentada por Schlemmer, (2016, 2017 e 2018) e Schlemmer, Backes e La Rocca (2016) como a modalidade de educação que integra a modalidade presencial física e a modalidade online, podendo combinar: eletronic learning, mobile learning, pervasive learning, ubiquitouslearning, immersive learning, gamification learning e Game-Based Learning $G B L$. No âmbito da aprendizagem pervasiva e ubíqua, as informações estão dispersas no espaço e nas coisas, possibilitando integrar espaços geográficos e espaços digitais virtuais, que podem ser acessadas por dispositivos móveis conectados a redes de comunicação sem fios. O conceito de ubiquidade,

${ }^{18}$ (Di Felice, 2017)

Interfaces da Educ., Paranaíba, v.11, n.32, p. 764 - 790, 2020 
vinculado à aprendizagem, indica que as TD potencializam a aprendizagem situada, ciente do contexto ("context-aware"), disponibilizando ao sujeito uma gama de informações "sensiveis" ao seu perfil, necessidades, ambiente e demais elementos que compõem seu contexto de aprendizagem, em qualquer lugar e momento. A essa possibilidade associamos tecnologias de localização (GPS, sistemas de navegação, sistemas de localização de pessoas, jogos móveis), tecnologias de identificação (etiquetas RFID e códigos QR, marcadores), sensores, e placas microcontroladoras (por ex., Arduino), dentre outras que podem estar presentes em locais, objetos, roupas e acessórios compondo aplicativos diversos, games e processos gamificados. A ubiquidade colabora para integrar os aprendizes em contextos de aprendizagem e no seu entorno, permitindo formar redes presenciais físicas e digitais virtuais entre pessoas, objetos, situações ou eventos. No contexto da ubiquidade, a IoT e os wearables se destacam, uma vez que objetos e coisas "inteligentes" podem estar pervasivamente presentes ao nosso entorno, prontos para interagir e cooperar conosco.

Nesse contexto, a nossa subjetividade, identidade e alteridade passam a ser constituídas também de forma híbrida, nesse movimento que emerge de relações interacionais em mundos de natureza distintas (físico e digital). A nossa vida hoje, é resultado desse hibridismo de uma vida "física" e "digital virtual", que vem sendo constituida por diferentes AN e ANH em rede, formando e sendo formados por essa nova cultura que se desenvolve. Nós habitamos, co-habitamos, e-habitamos e e-co-habitamos as plataformas, as mídias, os jogos, os ambientes, ao mesmo tempo em que eles nos habitam.

Dessa forma, o habitar do ensinar e do aprender precisam ser pensados numa perspectiva onlife, atópica, por meio de um novo tipo de ecologia, no qual elementos humanos, tecnológicos-informativos e ambientais interagem, constituindo uma hipercomplexidade (MORIN, 2011). Não se trata apenas de transferência de informações, mas da alteração dos elementos que passam a coabitar e interagir em conjunto.

Assim, a dimensão do habitar do ensinar e do aprender em contexto de hibridismo, inclui pensar esses processos enquanto ecologia, numa Interfaces da Educ., Paranaíba, v.11, n.32, p. 764 - 790, 2020 
condição habitativa que altera todos os interagentes que participam dessa rede ecossistêmica, o que pode então instigar inovação na educação.

\section{Algumas considerações...}

Nessa realidade hiperconectada, de acelerada e profundas transformações digitais, apresentadas anteriormente, cada vez mais ANH participam nas relações humanas e no processo de cognição, o que nos leva a reconhecer a natureza não apenas humana do conhecimento, mas o coengendramento, a codeterminação sujeito-objeto. No lugar da dicotomia entre $\mathrm{AH}$ e ANH estão as diferenças de agências e de ação, que se fazem entre os inúmeros agenciamentos possíveis e que atuam de formas distintas, contribuindo para o surgimento de uma nova compreensão de interação, enquanto emersão de si e do mundo.

Isso pode ser compreendido, ao olharmos para a ciência, que é o resultado da transformação do conhecimento criado entre humanos (teorias) e técnicas, tecnologias e instrumentos de observação. Para Di Felice (2019), o que diferencia o conhecimento científico de outros tipos de conhecimento é que a ciência, para conhecer, se apropria técnicas, instrumentos tecnológicos, para observar e medir os seus fenômenos. Essa relação não é instrumental, porque com a mudança e aprimoramento dos instrumentos técnicos, muda a própria concepção do fenômeno, como demonstra toda a história da ciência e, portanto, muda não somente a medição do fenômeno, mas a própria concepção do humano sobre o fenômeno e, portanto, o próprio cientista, o próprio humano.

Isso nos leva a afirmar que do ponto de vista da cognição, há uma diferença qualitativa entre usar uma TD (enquanto usuário, numa perspectiva utilitarista e reativa) e se apropriar, habitar (enquanto espaço de relações, de invenção, de criação, numa perspectiva de coengendramento e de codeterminação). Não é raro presenciarmos, no âmbito do ensinar e do aprender, o uso das TD, enquanto ferramenta, recurso, apoio, um uso meramente instrumental, reprodutivista da forma constituída do ensinar, para fazer mais do mesmo. Um exemplo é a incorporação das TD ao Interfaces da Educ., Paranaíba, v.11, n.32, p. 764 - 790, 2020 
currículo escolar como disciplina, enquanto o processo de inovação acontece fora do currículo, extra-classe, na forma de projetos, clube de robótica, dentre outros. Outro exemplo, está relacionado a parte significativa das ofertas de $\mathrm{EaD}$, que por meio das denominadas transposições didáticas, desenvolveram uma pedagogia massificadora e fordista, a qual possibilita multiplicar o ingresso de estudantes o que, em contrapartida, gera um alto índice de evasão e abandono.

A questão é que as epistemologias, as teorias e as metodologias que ainda subsidiam o ensinar e o aprender, tem origem num mundo pré-digital, cujo modelo de escola é massificador, reprodutivista, homogenizador. Não é possivel compreender a educação na atualidade, em rede, plataformas e construir ecossistemas de inovação na educação, tendo como subsídio epistemologias, teorias, metodologias e práticas constituídas numa época pré-digital, pela aplicação de um modelo educacional fordista.

Para que possamos compreender qualitativamente esse processo precisamos olhar para as plataformas, para as redes neuronais artificiais e outras formas de IA, para a IoT, enfim, para as redes que nos conectam, criando multiversos de diferentes naturezas, provocando uma transformação da nossa realidade e, superar o limite teórico-epistemológico e metodológico atual.

A epistemologia reticular parece fornecer uma importante contribuição para que possamos construir uma teoria cognitiva, suficientemente robusta que compreenda a cognição, não como algo exclusivo do humano mas, a partir da ontologia plana, onde AH e ANH estão no mesmo plano, cuja compreensão de inteligência e de conhecimento ultrapassa a visão antropocêntrica e, a aprendizagem possa ser compreendida para além da representação e solução de problemas, enquanto interpretação e invenção de problemas e, a interação, enquanto emersão simultânea de si e do mundo (KASTRUP, 2015), propiciado pela conectividade.

É preciso reconhecer que as redes, a conectividade está criando novas formas de ser e de estar no mundo, por meio de novas formas de interação, de presença, de expressar sentimentos, de aprender, de trabalhar... as Interfaces da Educ., Paranaíba, v.11, n.32, p. 764 - 790, 2020 
quais não se limitam mais aos espaços físicos, geográficos, mas se prolongam pelo digital, em todas as redes nas quais habitamos por meio dos nossos corpos tecnologizados ou info-corpos (DI FELICE, 2019). Estamos vivenciando uma transformação da ecologia e da sensorialidade dos corpos. A educação para essa e para as futuras gerações precisa habitar essa hiperrealidade e se transformar em atos de invenção, de pesquisa e não de consumo de um saber e um fazer já instituídos. Existe um ideário pedagógico, no entanto, ainda faltam plataformas e formação de professores, a fim de que seja possível fazer a inovação na educação. Precisamos pensar num currículo que se desenvolva por práticas itinerantes, inventivas, agregativas, as quais são arquitetadas no movimento do hibridismo e da multimodalidade. Uma concepção de currículo, que de acordo com Schlemmer e Moreira (2019) é desenvolvido a partir de epistemologias reticulares, que conectam $\mathrm{AH}$ e $\mathrm{ANH}$, num hibridismo de espaços, tempos, presenças, tecnologias e culturas. Nesse contexto, as diferentes áreas do saber, conhecimentos científicos e do cotidiano são legitimados e estão coengendrados, na perspectiva da aprendizagem enquanto invenção num habitar atópico, propiciando o engajamento com e no mundo para a transformação social e o desenvolvimento sustentável.

A partir da discussão apresentada podemos dizer que na atualidade, o habitar do ensinar e do aprender, num sentido amplo, se constitui enquanto percurso que se coengendra num habitar e co-habitar cada vez mais atópico, em contextos que são híbridos e multimodais. Dessa forma, as epistemologias reticulares podem contribuir, significativamente, para a superação de uma compreensão de conhecimento antropocêntrica e de uma compreensão do processo educativo centrado no objeto ou professor ou sujeito (aluno), tornando possivel desenhar diferentes contextos, na perspectiva da construção de ecossistemas de inovação na Educação.

Faz-se necessário então, compreender a Educação em tempos de transformação digital, enquanto espaço-tempo de relações, a partir de novas epistemologias reticulares, que provocam deslocamentos disruptivos no habitar do ensinar e o do aprender, a partir de interações ecossistêmicas. 


\section{Referências}

ALLEN, M. What was Web 2.0? Versions as the dominant mode of internet history. New Media \& Society, 15(2), 2013, p.260-275.

BRASIL. Ministério da Ciência, Tecnologia, Inovações e Comunicações. Estratégia Brasileira para a Transformação Digital (E-Digital). 2018. Disponivel em:

http:/ / www.mctic.gov.br/mctic/export/sites/institucional/estrategiadigital. pdf $>$. Acesso em setembro de 2019.

BROWN, Malcolm; et al., EDUCAUSE Horizon Report, Teaching and Learning Edition. Louisville, CO: EDUCAUSE, 2020.

CAPRA, F. A Teia da Vida: uma nova compreensão científica dos sistemas vivos. São Paulo: Cultrix, 1996.

CASTElls, M. A Sociedade em Rede. São Paulo: Paz e Terra, 1999.

DI FELICE, M. Paisagens pós-urbanas: o fim da experiência urbana e as formas comunicativas do habitar. São Paulo: Annablume, 2009. Coleção Atopos.

DI FELICE, M. Redes Sociais Digitais, epistemologias reticulares e a crise do antropomorfismo social. Revista USP, v. 22, 2012, p. 06-19.

DI FELICE, M. NET-ATIVISMO E ECOLOGIA DA AÇÃO EM CONTEXTOS RETICULARES. In Contemporanea: Revista de Comunicação e Cultura - v.11 - n.02 - mai-ago 2013 - p. 267-283. ISSN: 18099386 2. Disponível em: https://portalseer.ufba.br/index.php/contemporaneaposcom/article/view/8 235/6497. Acesso em setembro de 2019.

DI FELICE, M. Epistemologias reticulares e crise do humanismo. 2014. Disponivel em https://www.massimodifelice.net/epistemologia-reticulares.Acesso em setembro de 2019. 
DI FELICE, M. Net-ativismo: da ação social para o ato conectivo. São Paulo: Paulos Editora, 2017. Coleção Comunicação.

DI FELICE, M. As Epistemológicas Reticulares e as Ecologias Automatizadas do Conhecimento (comunicação oral). Reditec em Florianópolis. 2019. Disponivel em https://www.youtube.com/watch?v=zCg5H7RcIq0\&t=7791s. Acesso em setembro de 2019.

DI FELICE, M.; TORRES, J.; YANAZE, L.K. H. Redes digitais e sustentabilidade: as interac,ões com o meio ambiente na era da informac,ão. São Paulo: Annablume, 2012. Coleção Atopos.

FERnANDES, L., MORGADO, L., PAREDES, H., COELHO, A., \& RICHTER, J. Immersive learning experiences for understanding complex systems. In: Beck, Dennis; Peña-Rios, Anasol; Ogle, Todd; Economou, Daphne; Mentzelopoulos, Markos; Morgado, Leonel; Eckhardt, Christian; Pirker, Johanna; Koitz-Hristov, Roxane; Richter, Jonathon; Gütl, Christian; Gardner, Michael (orgs.), ILRN 2019 London-Workshop, Long and Short Paper, Poster, Demos, and SSRiP Proceedings from the Fifth Immersive Learning Research Network Conference. Graz, Áustria: Verlag der Technischen Universität Graz, 2019, p. 107-113.

FLORIDI, L. (ed.), The Onlife Manifesto: Being Human in a Hyperconnected Era. Springer Cham Heidelberg New York Dordrecht London, 2015. 255 p. Disponivel em: < https://link.springer.com/content/pdf/10.1007\%2F978-3319-04093-6.pdf>. Acesso em fevereiro de 2019.

KASTRUP, V. A cognição contemporânea e a aprendizagem inventiva. In: Políticas da Cognição. [S.1.]: Sulina, 2015, p. 91-110.

KHANNA, P. Connectography: Mapeando o futuro da civilização global. Random House, 2016.

LATOUR, B. Jamais fomos modernos. Rio de Janeiro: Editora 34, 1994. 
LATOUR, B. Reagregando o social: uma introdução à teoria do ator-rede. São Paulo: EDUSC, 2012.

LATOUR, B. Cogitamus: seis cartas sobre as humanidades científicas. São Paulo: Editora 34, 2016.

LÉVY, P. Cibercultura. Rio de Janeiro: Editora 34, 1999.

MOREIRA, J. A. RECONFIGURANDO ECOSSISTEMAS DIGITAIS DE APRENDIZAGEM COM TECNOLOGIAS AUDIOVISUAIS. Em Rede: Revista de Educação a Distância, v. 5, n. 1. 2018, p. 5-15.

MORGADO, L. C. Framework for Computer Programming in Preschool and Kindergarten. Vila Real, Portugal: UTAD, 2005. Tese (Doutoramento em Informática), Universidade de Trás-os-Montes e Alto Douro.

MORIN, E. Os sete saberes necessários à educação do futuro. Tradução de Catarian Eleonora F. da Silva e Jeanne Sawaya. São Paulo: Cortez; Brasília, DF: UNESCO, 2011.

PASSOS, E. Pensando a subjetividade com conceitos híbridos: a psicologia em interface com a filosofia e a biologia. In V. Kastrup, S. Tedesco, \& E. Passos, Politicas da Cognição. Porto Alegre, Brazil: Sulina. 2015, p. 63-88.

SCHLEMMER, E. Políticas e práticas na formação de professores a distância: por uma emancipação digital cidadã. In: Gatti, Bernardete Angelina; Junior, Celestino Alves da Silva; Nicoletti, Maria da Graça; Pagotto, Maria Dalva Silva. (Org.). Por uma política nacional de formação de professores. 1ed.São Paulo: Unesp, 2013, v. 1, p. 109-136.

SCHLEMMER, E. LABORATÓRIOS DIGITAIS VIRTUAIS EM 3D: ANATOMIA HUMANA EM METAVERSO, UMA PROPOSTA EM IMMERSIVE LEARNING. Revista e-Curriculum (PUCSP), 2014, v. 12, p. 2119-2157. 
SCHLEMMER, E. Mídia Social em Contexto de Hibridismo e Multimodalidade: o percurso da experiência na formação de Mestres e doutores. Revista Diálogo Educacional (PUCPR. Impresso), 2015a, v. 15, p. 399-421

SCHLEMMER, E. Gamification in Hybrid and Multimodal Coexistence Spaces : Design and Cognition in Discuss. In: 17th Annual International Conference Education, 2015, Athens. Gamification in Hybrid and Multimodal Coexistence Spaces: Design and Cognition in Discussão. Athenis (Greece): Gregory T. Papanikos, 2015b. v. 01. p. 03-15. ISSN: 2241-2891. Disponivel em: www.atiner.gr/papers.htm

SCHLEMMER, E. Games e Gamificação: uma alternativa aos modelos de EaD. Revista Iberoamericana de Educación a Distancia, 2016a, v. 19, p. 112 .

SCHLEMMER, E. Hibridismo, Multimodalidade e Nomadismo: codeterminação e coexistência para uma Educação em contexto de ubiquidade. In: Daniel Mill; Aline Reali. (Org.). Educação a distância, qualidade e convergências: sujeitos, conhecimentos, práticas e tecnologias. 1ed.São Carlos: EdUFSCar, 2016b, v. 1, p. 1-24.

SCHLEMMER, E. GAMIFICAÇÃO EM ESPAÇOS DE CONVIVÊNCIA HÍBRIDOS E MULTIMODAIS: A EDUCAÇÃO NA CULTURA DIGITAL. São Leopoldo, 2017. (Relatório de pesquisa).

SCHLEMMER, E. PROJETOS DE APRENDIZAGEM GAMIFICADOS: Uma metodologia inventiva para a educação na cultura híbrida e multimodal. MOMENTO - Diálogos em Educação, 2018, v. 27, p. 41-69.

SCHLEMMER, E. ; BACKES, L. Learning in Metaverses: Co-existing in Real Virtuality. 1. ed. Hershey: IGI Global, 2015, v. 1. 356 p.

SCHLEMMER, E.; BACKES, L.; LA ROCCA, F. L'Espace de coexistence hybride, multimodal, pervasif et ubiquitaire: le quotidien de l'éducation à la citoyenneté. Educação Unisinos (Online), 2016, v. 20, p. 297-306. 
SCHLEMMER, E. et al. ECoDI: A criação de um Espaço de Convivências Digital Virtual. In: XVII Simpósio Brasileiro de Informática na Educação XVII SBIE, 2006, Brasília. XVII Simpósio Brasileiro de Informática na Educação - XVII SBIE, 2006.

SCHLEMMER, E.; LOPES, M.C.; AMARAL, A.; FISCHER, G. D.; PRINT: Transformação Digital e Humanidades. 2018.(Projeto de Pesquisa)

SCHLEMMER, Eliane; MOREIRA, José A . MODALIDADE DA PÓSGRADUAÇÃO STRICTO SENSU EM DISCUSSÃO: dos modelos de EaD aos ecossistemas de inovação num contexto híbrido e multimodal. EDUCACAO UNISINOS (ONLINE), v. 23, 2019, p. 689-708.

SCHLEMMER, E.; TREIN, D.; OLIVEIRA, C. J. de . Metaverso: a telepresença em Mundos Digitais Virtuais 3D por meio do uso de avatares. In: XIX Simpósio Brasileiro de Informática na Educação - SBIE, 2008, Fortaleza. XIX Simpósio Brasileiro de Informática na Educação - SBIE. fortaleza: Universidade Federal do Ceará, 2008. v. 1. p. 1-10.

SCHWAB, K. A quarta revolução industrial. São Paulo, Edipro, 2016.

SERRES, M. Polegarzinha. Rio de Janeiro: Bertrand Brasil, 2013.

TREIN, D.; SCHLEMMER, E. Projetos de Aprendizagem Baseados em Problema no Contexto da Web 2.0: Possibilidades para a Prática Pedagógica. Revista e-Curriculum (PUCSP), v. 4, 2009, p. 1-20.

WEF-WORDL ECONOMIC FORUM. New Vision for Education: Unlocking the Potential of Technology. Cologny/Geneva: World Economic Forum, 2015. 